\title{
REDISTRIBUTION AND OCCUPATIONAL CHOICE IN A SCHUMPETERIAN GROWTH MODEL
}

\author{
CECILIA GARCÍA-PEÑALOSA \\ JEAN-FRANÇOIS WEN
}

CESIFO WORKING PAPER NO. 1323

CAtegory 5: Fiscal Policy, Macroeconomics AND Growth NOVEMBER 2004 


\title{
REDISTRIBUTION AND OCCUPATIONAL CHOICE IN A SCHUMPETERIAN GROWTH MODEL
}

\begin{abstract}
We consider an R\&D-driven endogenous growth model in which innovation is risky and agents are risk averse. Growth is determined by the occupational choice of agents who can either work in production for a wage or become entrepreneurs. In this context, we examine the impact of redistributive taxation and compute socially optimal tax rates. Redistribution acts as social insurance, thus encouraging innovation and accelerating growth. The general equilibrium effects of the reallocation of labour induced by taxation can offset the direct distributive impact of taxes and result in a Pareto improvement. Optimal tax rates are a humpshaped function of the intertemporal spillover effect.
\end{abstract}

JEL Code: H21, O3, O4.

Keywords: growth, innovation, optimal taxation, occupational choice.

\author{
Cecilia García-Peñalosa \\ GREQAM \\ Centre de la Vieille Charité \\ 2 rue de la Charité \\ 13002 Marseille \\ France \\ penalosa@ehess.cnrs-mrs.fr
}

\author{
Jean-François Wen \\ University of Calgary \\ 2500 University Drive \\ NW, SS 418 Calgary \\ Alberta, T2N $1 N 4$ \\ Canada \\ wen@ucalgary.ca
}

We would like to thank seminar participants at GREQAM and CORE. Part of this research was undertaken while García-Peñalosa was visiting the CES (Munich). 


\section{Introduction}

The revival of interest in the relationship between inequality and growth has led economists to raise new questions about the effects of redistribution. The traditional incentive argument that redistribution reduces physical capital accumulation has been emphasised by models such as those of Alesina and Rodrik (1994) and Persson and Tabellini (1994). However, such results are reversed once there are capital market imperfections. Redistribution can then become growth enhancing either through an 'opportunity creation effect,' as in Galor and Zeira (1993), or through an 'incentive mechanism' in the presence of moral hazard, in Aghion and Bolton (1997). A possible reading of this literature is that redistribution fosters growth only in developing countries, where credit markets are highly imperfect and growth is driven by factor accumulation. Meanwhile, in industrial economies, which have well-functioning financial institutions, democratic political systems, and active $R \& D$ sectors, redistribution is likely to slow down growth. In this paper we argue that industrial economies are characterised by a different type of market imperfection, namely the absence of private insurance for risk-taking entrepreneurs, and we examine the effect of redistribution on occupational choice when innovation is uncertain and agents risk-averse.

There is plenty of evidence on the sizeable risks faced by entrepreneurs. There were on average 78,711 business failures per year in the United States from 1990 to 1997; 61.5 per cent of businesses exit within five years, and the founder of a private company faces a risk of about 10 per cent of losing all his/her investment in the first ten years (Dun and Bradstreet Corporation; Dunne et al., 1988; Moskowitz and Vissing-Jorgensen, 2002; respectively). The crosssectional standard deviation of self-employment earnings is substantially higher than wages from paid employment (Hamilton, 2000). At the same time, a number of authors have established the importance of taxation in encouraging or discouraging self-employment and entrepreneurship. For example, Bird (2001) examines cross-country differences in the Welfare State and finds that greater social spending encourages risk-taking. ${ }^{1}$

This evidence contrasts with the standard approach in the growth literature, where, despite major steps to provide microfoundations for the innovation process, risk-aversion and insurance have not received much attention. We develop a discrete-time, overlapping generations, variant of the Schumpterian growth model of Aghion and Howitt (1992), in which agents are risk-averse. There are two sources of inequality - that between skilled and unskilled agents which are ex ante different, and that among skilled agents who choose different occupations and become different ex post. In particular, some skilled workers will choose to work in production for fixed wages, while others will become entrepreneurs/researchers and receive random profits. It is this endogenous choice of occupation which drives the growth process. Using this framework, we address two questions. Since redistribution provides insurance for entrepreneurs, how does redistribution affect growth? Since innovations create intertemporal

\footnotetext{
${ }^{1}$ See also Stabile (2004), Bruce (2000), and Gentry and Hubbard (2000).
} 
spillovers, how do growth considerations affect optimal tax rates?

Several broad results emerge from our analysis. First, we show that the net effect of introducing a small amount of redistributive taxation is to insure researchers in the case of failure, hence increasing the attractiveness of entrepreneurship. This raises the amount of research undertaken and accelerates the growth rate, relative to the laissez-faire equilibrium.

Second, we consider the general equilibrium effects of taxes. When the number of researchers increases, the number of skilled wage-earners falls, raising their equilibrium wage. This implies that skilled workers may experience an increase in their net incomes despite being net fiscal contributors. At the same time, a reduction in the number of skilled wage-earners reduces the marginal productivity and the wage of unskilled workers, although they benefit directly from fiscal transfers. It turns out that the overall effect of redistribution can be (but need not be) simultaneously growth-enhancing and Pareto-improving.

Third, we use numerical examples to examine how optimal linear tax rates vary with key parameters, such as the degree of intertemporal knowledge spillovers. We find that in the absence of growth, that is, when entrepreneurship is a purely rent-seeking activity, optimal tax rates are substantially lower than when entrepreneurship generates technological change. This indicates that the social planner can use redistribution both to reduce inequality and to foster innovation. We also show that the optimal tax rate is a hump-shaped function of the spillover factor. The reason for this is that the Schumpeterian model implies that there is a social cost of innovation due to the monopoly exercised by the successful innovator. For weak intertemporal spillovers, the optimal tax rate is driven by static equity considerations, but when spillovers are large the loss due to monopoly becomes important. The planner then wants to slow the rate of innovation, and hence reduces the amount of redistribution. ${ }^{2}$

Our paper bridges two strands of literature: one concerns the impact of redistribution on growth, the other the effect of social insurance on occupational choice. The idea that redistribution can act as social insurance when private risk-pooling arrangements are absent was first noted by Eaton and Rosen (1980) and Varian (1980). Further studies by Kanbur (1981), Peck (1989), and Boadway, Marchand and Pestieau (1991) examined how redistribution affects the occupational choice between risky entrepreneurship and paid employment. A central concern in these papers is the implication of occupational choice for optimal taxation. The models used, however, are static as entry into entrepreneurship is assumed to have no impact on innovation or growth. As a result the social planner faces a tradeoff since greater redistribution reduces (ex post) inequality, but, because it provides more insurance against business failures, it encourages excessive risk taking (i.e. leads to too many entrepreneurs). The introduction

\footnotetext{
${ }^{2}$ This effect is equivalent to, though not the same as, the 'business stealing' effect in Aghion and Howitt (1992). In their model, infinite patent lives imply that the social cost of innovation is the transfer of profits from one monopolist to another. In our model, finite patent lives will imply that there is competitive production when patents expire with no new innovations occurring. Both effects play the same role, tending to make the laissez-faire growth rate excessive.
} 
of a dynamic aspect to entrepreneurship implies, on the other hand, that the provision of insurance may be desirable from the planner's point of view.

Two papers are particularly close to our work. Caucutt et al. (2003) examine the impact of tax progressivity on growth, when individuals invest in human capital, and find that greater progressivity can accelerate growth. Their work differs from our's in that they consider the risk associated with educational investments, and how progressivity may reduce this risk. However, some authors have argued that remaining unskilled actually entails a greater risk due to the greater probability of being unemployed, and that education is precisely a way to reduce this risk. ${ }^{3}$ Chou and Talmain (1996) examine an R\&D model in which redistribution can be both growth-enhancing and Pareto improving. Their mechanism relies on the elasticity of individual labor supplies. Redistribution impacts growth because an individual's wealth affects her consumptionleisure tradeoff and hence determines her labor supply. Under certain conditions, redistribution may raise the aggregate labor supply and hence the growth rate. Furthermore, since agents are infinitely lived, faster growth offsets the static loss imposed by redistribution on rich individuals, and a Pareto improvement may be possible. Our analysis differs from this approach in two crucial aspects. First, allowing for risk-aversion implies that redistribution affects innovation through occupational choice rather than through a 'scale effect.' Second, the Pareto improvement obtained by Chou and Talmain is due to the growth-effect offsetting the direct redistribution effect, and would not necessarily hold if individuals had finite lives. We focus on an overlapping generations setup and consider the effect of redistribution on the welfare of a particular generation. This means that we do no need to consider the weight give by the planner to successive generations.

The next section presents the model. Section 3 describes the equilibrium of the model. Section 4 considers analytically the effect of introducing a small amount of redistribution. The intertemporal social welfare function is derived and discussed in section 5. Section 6 contains numerical simulations of the optimal tax rates to show the policy implications of the model. Section 7 concludes.

\section{The Model}

\subsection{Population}

A population of size $N$ consists of $L$ unskilled and $H$ skilled workers, each living for two periods. There are overlapping generations with constant regeneration of the population, so that in each period half the population is young and half is old. Unskilled workers are always employed in manufacturing. Skilled workers make an occupational choice at the beginning of their lives, choosing between being an entrepreneur or a manufacturing worker.

Entrepreneurs (also called 'researchers') undertake research in order to invent a higher quality intermediate good and obtain a patent for it next period. The

\footnotetext{
${ }^{3}$ Gould, Moav, and Weinberg (2001).
} 
mass of entrepreneurs in period $t$ is denoted $R_{t}$. The remaining $M_{t}=H-R_{t}$ skilled workers, whom we denote as 'producers,' are hired for fixed wages to manufacture the intermediate good using the incumbent technology.

The production of final goods uses the most recently invented type of intermediate good and unskilled labor as inputs. It is assumed that skilled workers can always choose to perform unskilled work, so they can never be worse off than the unskilled.

\subsection{Production Technologies}

A single homogeneous final good is produced by a competitive sector according to the production function

$$
Y_{t}=A_{t} x_{t}^{\theta} L^{1-\theta},
$$

where $A_{t}$ is a parameter indicating total factor productivity, which depends on the 'quality' of the intermediate good used, and $x_{t}$ is the amount of intermediate good employed. The price of the final good is the numeraire.

The intermediate good is produced using skilled labor alone according to the linear technology

$$
x_{t}=M_{t} .
$$

The intermediate good sector may be monopolistic or competitive depending on whether or not the highest quality of the intermediate good is under patent.

Each innovation increases the value of $A_{t}$ by a factor $\gamma>1$, with $A_{t+1}=\gamma A_{t}$ if an innovation occurs in $t$ and $A_{t+1}=A_{t}$ if no innovation occurs. We assume that innovations are drastic, so that only the latest quality of the good will be produced at each point in time. ${ }^{4}$

Similar to the assumptions in Cooper et al. (2001), the probability of at least one entrepreneur discovering the 'next' quality of intermediate good during period $t$ is

$$
\operatorname{Pr}(\text { at least one innovator })=\lambda R_{t}^{\eta}
$$

where $0 \leq \eta \leq 1$, implying that the technology of discovery features duplication in research (a form of decreasing returns to scale). ${ }^{5}$ At most one patent is awarded each period. We assume that, conditional on an innovation occurring, the probability that the patent is awarded or not awarded to a given entrepreneur is, respectively,

$\operatorname{Pr}($ patent to a given entrepreneur|an innovation occurs $)=1 / R_{t}$ $\operatorname{Pr}$ (no patent to a given entrepreneur|an innovation occurs) $=\left(R_{t}-1\right) / R_{t}$.

\footnotetext{
${ }^{4}$ Assuming non-drastic innovations would leave unchanged our qualitative results.

${ }^{5}$ Another possibility is that there is a spillover of knowledge among researchers in the current period, implying $\eta>1$. However, we do not explore it here.
} 
We require $R_{t} \geq 1$ for the probability distribution to be defined. ${ }^{6}$

A patent is assumed to last for a single period, which is the period following the discovery. After that period, anyone can freely copy the technology. Lastly, there is no storage (nor external lending/borrowing) in this economy; all production is consumed in the current period.

\subsection{Market Structure, Profits and Wages}

The final goods sector is competitive. However, the market structure for intermediate goods depends on whether or not an innovation occurred the previous period. The intermediate good is produced by a patent-protected monopolist in period $t$ if and only if an innovation occurred at $t-1$. If there were no innovation at $t-1$, then at $t$ there are no intermediaries under patent and there is competition in the sector. ${ }^{7}$

Let $\phi_{t} \in\{0,1\}$ denote the market structure in period $t$, with $\phi_{t}=1$ indicating monopoly, $\phi_{t}=0$ competition. Wage rates and aggregate labor supplies will depend on the market structure and are therefore indexed by $\phi_{t}$. For convenience, we shall drop the period $t$ time subscript on $\phi$. Let $w_{t}^{\phi}$ denote the wage of skilled labor used to produce the intermediate good; thus $w_{t}^{1}$ is the wage rate if in period $t$ the intermediate goods market is a monopoly, and $w_{t}^{0}$ is the wage rate when there is competition. Similarly, $v_{t}^{\phi}$ denotes the unskilled wage; $M_{t}^{\phi}$ and $R_{t}^{\phi}$ are the allocations of skilled labor to manufacturing and entrepreneurship, while $Y_{t}^{\phi}$ is output. All unskilled labor $L$ is employed in production in both states and paid its marginal product.

\subsubsection{Monopoly}

We first consider the case where there is a monopolist in the intermediate goods sector in period $t ; \phi=1$. Differentiating (1) to obtain the inverse demand function for intermediate goods, we can write the monopolist's problem as

$$
\max _{x_{t}} \Pi=A_{t} \theta x_{t}^{\theta} L^{1-\theta}-w_{t}^{1} x_{t}
$$

The profit maximizing production of $x_{t}$ is therefore, $x_{t}=\left(A_{t} \theta^{2} / w_{t}^{1}\right)^{\frac{1}{1-\theta}} L$. This expression, together with the market-clearing condition for skilled workers, $x_{t}=M_{t}^{1}$, gives the skilled wage $w_{t}^{1}$, the unskilled wage $v_{t}^{1}$, and the monopolist's

\footnotetext{
${ }^{6}$ If $R_{t}<1$, then the conditional probabilities above are assumed to be truncated at 1 and 0 , respectively. We shall focus on interior solutions.

${ }^{7}$ There is some similarity between our setup and the model of Lambson and Phillips (2004), where they assume that monopoly prevails if there is a sole innovator in the period, while Bertrand competition prevails if there are multiple innovators.
} 
profit $\Pi_{t}$ as

$$
\begin{aligned}
w_{t}^{1} & =\theta^{2} \frac{Y_{t}^{1}}{M_{t}^{1}}, \\
v_{t}^{1} & =(1-\theta) \frac{Y_{t}^{1}}{L}, \\
\Pi_{t} & =(1-\theta) \theta Y_{t}^{1} .
\end{aligned}
$$

\subsubsection{Competition}

Suppose there is no innovation in period $t-1$. Any previous patent has now expired and there is competition in the intermediate goods sector at $t$. The price of intermediate goods must then equal their marginal cost, which is just the producer's wage, $w_{t}^{0}$, and zero profits are earned in the intermediate goods sector. The skilled and unskilled wages are then

$$
\begin{aligned}
w_{t}^{0} & =\theta \frac{Y_{t}^{0}}{M_{t}^{0}}, \\
v_{t}^{0} & =(1-\theta) \frac{Y_{t}^{0}}{L} .
\end{aligned}
$$

Two things are worth noting. First, from the wage equations (4), (5), (7), and (8), we have that $w_{t}^{\phi}>v_{t}^{\phi}$ if $L / M_{t}^{\phi}>(1-\theta) / \theta^{1+\phi}$. A sufficient condition, therefore, for ensuring that skilled workers always receive higher wages than unskilled workers is $L / H>(1-\theta) / \theta^{2}$. The relative abundance of unskilled labor is one source of income inequality in this economy, the other being the risk associated with the research process, as we will see below. Second, the level of output in periods in which there is monopoly will differ from that in periods where there is competition. In general, output will be greater when there is competition. More research will usually be undertaken under monopoly, implying that the number of producers is also higher under competition.

\subsection{Taxation}

We are interested in the optimal linear tax system, i.e. in a system having the general form of $T(I)=-B+\tau I$, where $I$ is individual income, $\tau$ the tax rate, and $B$ a demogrant. The tax and transfer policy we study has two important features. First, an individual is paid a transfer $B$ in the first period of her life. However, she will pay taxes when young if she is unskilled or a producer, and when old if she is an entrepreneur, as will be clear below. Second, since there are two states of the world, we allow the government to tax differently in those two states. The two taxes have different effects on the allocation of labor, and there is no reason why they should be set at the same level. In the numerical simulations in section 6 we also consider cases where the tax rates are constrained to be identical. 
The government holds a balanced budget in each period, so that its budget constraints are

$$
\begin{aligned}
N \cdot B_{t}^{1} & =\tau^{1}\left(\Pi_{t}+w_{t}^{1} M_{t}^{1}+v_{t}^{1} L\right) \\
& =\tau^{1} Y_{t}^{1}
\end{aligned}
$$

and

$$
\begin{aligned}
N \cdot B_{t}^{0} & =\tau^{0}\left(w_{t}^{0} M_{t}^{0}+v_{t}^{0} L\right) \\
& =\tau^{0} Y_{t}^{0} .
\end{aligned}
$$

Note that the tax system considers individual uncertainty but ignores aggregate uncertainty, as no resources are transferred between periods with different output levels.

\subsection{Utility}

Skilled workers make an occupational choice between working in manufacturing $(m)$ or entrepreneurship $(e)$. All individuals supply one unit of work effort when they are young. When they are old they do not work. Wages are paid to producers in the period that they work (therefore, when they are young). A successful entrepreneur that innovates at $t$ obtains a patent for the intermediate good, and hires a new generation of young workers to manufacture the innovation at $t+1$. Entrepreneurs hence receive income and pay taxes only when they are old.

Individuals have identical utility functions and it is assumed that consumption, $C$, when young or old are perfect substitutes. The utility of someone born in period $t$ is assumed to be given by

$$
U_{t}\left(C_{t}, C_{t+1}\right)=\left(C_{t}+C_{t+1}\right)^{\alpha}, \quad 0<\alpha<1 .
$$

Given the assumptions made above regarding the timing of earnings, it is necessarily the case that individuals always work when they are young, but the period in which they consume depends on whether they are manufacturing workers or entrepreneurs.

Given the probability of success, the expected utility of an entrepreneur is:

$$
U_{e t}^{\phi}=\lambda\left(R_{t}^{\phi}\right)^{\eta-1}\left(C_{\pi t+1}^{\phi}\right)^{\alpha}+\left(1-\lambda\left(R_{t}^{\phi}\right)^{\eta-1}\right)\left(B_{t}^{\phi}\right)^{\alpha},
$$

where $\lambda\left(R^{\phi}\right)^{\eta-1}$ is the unconditional probability of winning the patent race and the term $C_{\pi t+1}$ is the consumption in period $t+1$ of a period- $t$ patent winner,

$$
\begin{aligned}
C_{\pi t+1}^{\phi} & \equiv\left(1-\tau^{1}\right) \Pi_{t+1}+B_{t}^{\phi} \\
& =\left(\left(1-\tau^{1}\right)(1-\theta) \theta Y_{t+1}^{1}+\frac{\tau^{\phi} Y_{t}^{\phi}}{N}\right) .
\end{aligned}
$$


Now suppose that a skilled individual chooses to become a producer, rather than an entrepreneur. Then $U_{m t}^{\phi}=\left(\left(1-\tau^{\phi}\right) w_{t}^{\phi}+B_{t}^{\phi}\right)^{\alpha}$, which can be written as

$$
U_{m t}^{\phi}=\left(Y_{t}^{\phi}\right)^{\alpha}\left(\left(1-\tau^{\phi}\right) \frac{\theta^{1+\phi}}{M_{t}^{\phi}}+\frac{\tau^{\phi}}{N}\right)^{\alpha} .
$$

An unskilled worker has no occupational choice and receives a utility of $U_{u t}^{\phi}=\left(\left(1-\tau^{\phi}\right) v_{t}^{\phi}+B_{t}^{\phi}\right)^{\alpha}$. That is,

$$
U_{u t}^{\phi}=\left(Y_{t}^{\phi}\right)^{\alpha}\left(\left(1-\tau^{\phi}\right) \frac{(1-\theta)}{L}+\frac{\tau^{\phi}}{N}\right)^{\alpha}
$$

\section{Equilibrium}

\subsection{Occupational Choice}

At the start of her life a skilled worker makes her occupational choice in order to maximize expected utility, given the market structure for intermediate goods. Arbitrage will then determine the equilibrium allocation of skilled individuals across occupations in each state, $R_{t}^{\phi}$. If an internal solution exists (i.e., $1<$ $R_{t}^{\phi}<H$ and $\lambda\left(R_{t}^{\phi}\right)^{\eta}<1$ ), it is determined from the equal-utilities conditions

$$
\begin{aligned}
& U_{m}^{1}\left(M_{t}^{1} ; \tau^{1}\right)=U_{e}^{1}\left(R_{t}^{1}, M_{t+1}^{1} ; \tau^{1}\right) \\
& U_{m}^{0}\left(M_{t}^{0} ; \tau^{0}\right)=U_{e}^{0}\left(R_{t}^{0}, M_{t+1}^{1} ; \tau^{1}, \tau^{0}\right)
\end{aligned}
$$

where the utilities are given by (11)-(13).

\subsection{Steady State Equilibrium}

Note from (15) and (16) that the occupational choice at period $t$ depends implicitly on expectations about future research. We assume perfect forecasting, and focus on the steady state equilibrium where, given the policy variables $\tau^{1}$ and $\tau^{0}$, we have $M^{\phi}=M_{t}^{\phi}$ and $R^{\phi}=R_{t}^{\phi}$ for all $t .{ }^{8}$

Using (11)-(13) in (15) and (16) the steady state equal-utilities conditions determining occupational choices can be written as,

$$
\begin{aligned}
\left(\frac{\left(1-\tau^{1}\right) \theta^{2}}{H-R^{1}}+\frac{\tau^{1}}{N}\right)^{\alpha}\left(Y^{1}\right)^{\alpha}= & \lambda\left(R^{1}\right)^{\eta-1}\left(\left(1-\tau^{1}\right)(1-\theta) \theta \gamma+\frac{\tau^{1}}{N}\right)^{\alpha}\left(Y^{1}\right)^{\alpha} \\
& +\left(1-\lambda\left(R^{1}\right)^{\eta-1}\right)\left(\frac{\tau^{1}}{N}\right)^{\alpha}\left(Y^{1}\right)^{\alpha}
\end{aligned}
$$

\footnotetext{
${ }^{8}$ See Aghion and Howitt $(1992,1998)$ for a discussion of the role of expectations. Our assumption that individuals live for two periods means they need only forecast one period ahead.
} 
and

$$
\begin{aligned}
& \left(\frac{\left(1-\tau^{0}\right) \theta^{2}}{H-R^{0}}+\frac{\tau^{0}}{N}\right)^{\alpha}\left(Y^{0}\right)^{\alpha} \\
= & \lambda\left(R^{0}\right)^{\eta-1}\left(\left(1-\tau^{1}\right)(1-\theta) \theta \gamma\left(\frac{H-R^{1}}{H-R^{0}}\right)^{\theta}+\frac{\tau^{0}}{N}\right)^{\alpha}\left(Y^{0}\right)^{\alpha} \\
& +\left(1-\lambda\left(R^{0}\right)^{\eta-1}\right)\left(\frac{\tau^{0}}{N}\right)^{\alpha}\left(Y^{0}\right)^{\alpha},
\end{aligned}
$$

where the left-hand side in each of (17) and (18) is the utility of a producer and the right-hand side is an entrepreneur's expected utility. Of course, the common term $\left(Y_{t}^{\phi}\right)^{\alpha}$ in each equation can be cancelled out. (17) and (18) together determine the equilibrium values of $R^{1}$ and $R^{0}$ as a function of the two tax rates and model parameters. ${ }^{9}$

\subsection{The Laissez-faire Equilibrium}

To illustrate the equilibrium, we consider the benchmark case of the economy without intervention. In this case, there is no insurance, hence the entrepreneurs who fail to discover a new quality receive no income. Since $\eta \leq 1$, the interior equilibrium for the number of researchers in the monopoly state is unique and given implicitly by the solution to

$$
\frac{H-R^{1}}{\left(R^{1}\right)^{(1-\eta) / \alpha}}=\frac{1}{\gamma \lambda^{1 / \alpha}} \frac{\theta}{(1-\theta)}
$$

assuming that $R^{1}$ is greater than one, i.e; if $\gamma \lambda^{1 / \alpha}$ is large enough.

When the intermediate goods market is competitive, the laissez-faire equilibrium for $R^{0}$ is unique and given by

$$
\frac{\left(H-R^{0}\right)^{1-\theta}}{\left(R^{0}\right)^{(1-\eta) / \alpha}}=\frac{1}{\gamma \lambda^{1 / \alpha}} \frac{1}{(1-\theta)\left(H-R^{1}\right)^{\theta}},
$$

with the value of $R^{1}$ from (19). Equations (19) and (20), together with the fact that $\theta<1$, imply that $R^{0}<R^{1}$. In periods in which the intermediate sector is competitive, there is a greater demand for production workers, their wages are higher, and the number of producers increases. Consequently, there will be fewer researchers and a lower probability of innovation. However, output is higher in the competition state as a larger number of skilled workers are employed in manufacturing.

\footnotetext{
${ }^{9}$ It is easy to see that there is a single solution for $R^{1}$ in (17). As for $R^{0}$, after dividing both sides of $(18)$ by $\left(Y^{0}\right)^{\alpha}$, the left-hand side of the resulting equation is increasing and convex in $R^{0}$ (and asymptotic at $R^{0}=H$ ) but the right-hand side is U-shaped, which means the 'curves' may intersect more than once. In our numerical simulations the solution for $R^{0}$ were unique.
} 
The comparative statics are easily established and are analogous to those in Aghion and Howitt (1992). The only new aspect is the introduction of riskaversion. As expected, greater risk-aversion (lower $\alpha$ ) decreases entrepreneurship.

Lemma 1 The laissez-faire equilibrium values of $R^{1}$ and $R^{0}$ are increasing in $\lambda$, $\gamma$, and $\alpha$, and decreasing in $\theta$.

\subsection{Innovation and Long-Run Growth}

The change in output between periods $t$ and $t+1$ can be written as

$$
\ln \left(\frac{Y_{t+1}}{Y_{t}}\right)=\ln \left(\frac{A_{t+1}}{A_{t}}\right)+\ln \left(\frac{M_{t+1}}{M_{t}}\right) .
$$

An innovation has two effects: on the one hand it increases output because of the higher quality of the intermediate good, on the other it reduces it if the economy moves from the competitive to the monopolistic state. Furthermore, there may be increases in output in periods in which the technology is unchanged, as the end of the patent life will bring about an increase in the amount of the intermediate input used. However, the natures of these two effects are different. Technological advances have permanent effects on welfare, while changes in the amount of intermediate good used are only temporary, and result in fluctuations along the trend due to one-period changes in the level of manufacturing employment. We therefore focus on the expected rate of technological change, $g_{t}$, where

$$
g_{t}=E\left(\ln A_{t+1}-\ln A_{t}\right) .
$$

The expected rate of technical change at any future date $t$ depends on the current state, since the probabilities of innovation in each period follow a statedependent Markov chain. In the long run, however, the state-dependent Markov process converges to an invariant probability distribution, generating a simple Bernouilli process for innovation (see appendix), in which there is a constant chance $q$ that an innovation occurs, regardless of the current or 'initial' state $\phi_{0}$, where

$$
q=\frac{q^{0}}{1-q^{1}+q^{0}}
$$

and $q^{\phi}=\lambda\left(R^{\phi}\right)^{\eta}$ is the probability of innovation in the current period when the current state is $\phi$. The expected long-run growth rate, $g$, is then

$$
g=q \ln \gamma
$$

Clearly, the long-run probability of innovation, and hence the growth rate, are increasing in the number of researchers in both states. The question we address in the next section is whether redistribution encourages or discourages economic growth through the impact of taxation on the probability of innovation. 


\section{Equilibrium Effects of Redistribution}

\subsection{Redistribution and Research}

Central to our analysis of optimal taxation with occupational choice is the idea that redistribution can be used to stimulate entrepreneurship and growth. We address the issue analytically by considering the effect of introducing a small amount of taxation.

Proposition 1 For an economy in the laissez-faire equilibrium:

1. Introducing a small amount of redistribution in the competition state $\left(\tau^{0} \rightarrow\right.$ $0^{+}$) increases research in the competition state and does not affect it in the monopoly state. The effect is to increase the long-run probability of innovation $q$.

2. Introducing a small amount of redistribution in the monopoly state $\left(\tau^{1} \rightarrow\right.$ $0^{+}$) increases research in the monopoly state and reduces it in the competition state. If the skilled population $(H)$ is not too small, the overall effect is to increase the long-run probability of innovation $q$.

Proof: See appendix.

From equations (17) and (18), the effect of $\tau^{0}$ is straight-forward. The tax has no direct impact on $R^{1}$. It provides an income for unsuccessful entrepreneurs, but does not affect the net profitability of an innovation, thus shifting upwards $U_{e}^{0}$. The utility of producers will decrease with $\tau^{0}$ as long as they are net contributors, shifting $U_{m}^{0}$ downwards. As a result $\tau^{0}$ unambiguously increases the number of individuals who choose to become researchers in the competition state and hence raises the long-run probability of innovation.

The effect of $\tau^{1}$ on $U_{e}^{1}$ represents the 'social insurance effect' on entrepreneurs during the monopoly state. This effect consists first of an 'insurance premium' which is the net fiscal contribution of a successful innovator (which can be assumed positive in any interesting application). The premium captures the traditional argument that taxes discourage entrepreneurship. Second, unsuccessful entrepreneurs receive a 'compensation payment' that increases their utility and encourages entrepreneurship. The significance of social insurance for an entrepreneur is evident in evaluating the partial derivative of her utility at $\tau^{1}=0$, which is easily seen to be infinite. ${ }^{10}$ The utility of producers decreases with $\tau^{1}$ as long as they are net contributors. ${ }^{11}$ As a result, the number of entrepreneurs in the monopoly state rises. Figure 1 depicts the comparative static effect of $\tau^{1}$. For any given number of entrepreneurs, a marginal imposition of $\tau^{1}$ shifts $U_{e}^{1}$ upwards and $U_{m}^{1}$ downwards, raising the equilibrium value of $R^{1}$.

\footnotetext{
${ }^{10}$ In reality, many entrepreneurs may have other forms of wealth to consume in the event of failure, but this merely underscores the point that, in the absence of social insurance, potential entrepreneurs may delay their entry into business until they have funds to fall back on.

${ }^{11} \mathrm{~A}$ sufficient condition for this is $L / H>\left(1-\theta^{2}\right) / \theta^{2}$.
} 
Figure 1

The impact of taxes on occupational choice

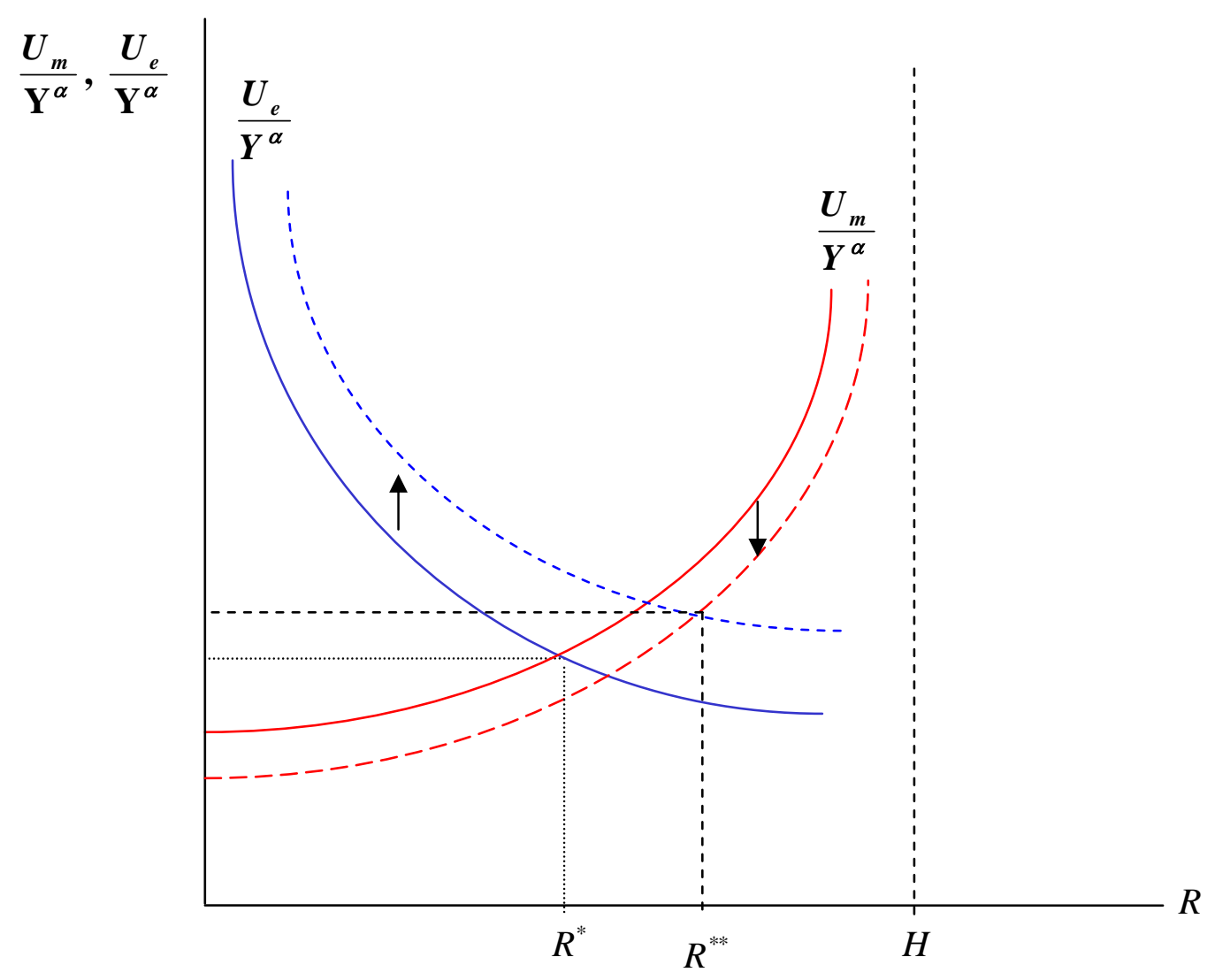


Consider now the effect of $\tau^{1}$ on the equilibrium for $R^{0}$. The tax tends to reduce $R^{0}$ for two reasons. There is a direct tax effect: given output, anticipated net monopoly profits fall. There is also an indirect effect: the increase in research in the monopoly state raises anticipated skilled wages and hence lowers the gross profit of a successful entrepreneur. Consequently the amount of research done in the competition state falls.

Recall that $q$ increases in both arguments $R^{1}$ and $R^{0}$, implying that $\tau^{1}$ has opposing effects on the long-run probability of innovation. Proposition 1 (part 2 ) states that the positive effect of $R^{1}$ on growth will dominate if the number of skilled workers is sufficiently large. The reason for this is that a large skilled labor force ensures that monopoly profits do not fall too much as skilled workers move away from production in the monopoly state (i.e. as $R^{1}$ increases), and hence results in a small reduction in $R^{0}$.

Two remarks are in order. First, the effect of redistributive taxation on growth is due to the provision of insurance that encourages risk-taking. It can easily be checked from equations (17) and (18) that if agents were riskneutral (i.e. $\alpha=1$ ), redistribution would have no impact whatsoever on the occupational choice, and hence would not affect the growth rate. Second, the effects of large tax rates are ambiguous. In particular, a large $\tau^{1}$ may imply that the 'insurance premium' paid in case of success offsets the utility gain due to the 'compensation payment' received in case of failure, reducing the number of researchers. This is the standard argument that taxation of high incomes reduces innovation. Our numerical examples below show, however, that the insurance effect tends to dominate and that redistribution increases growth, when tax rates are set optimally.

\subsection{Redistribution and Wages}

Redistribution also affects social welfare by changing the equilibrium wage rates and the expected utilities of skilled and unskilled agents. We have the following results.

Proposition 2 For an economy in the laissez-faire equilibrium:

1. Introducing a small amount of redistribution in the competition state increases (decreases) the wage and utility of skilled (unskilled) workers in the competition state, and has no effect on wages and utilities in the monopoly state.

2. Introducing a small amount of redistribution in the monopoly state increases (decreases) the wage and utility of skilled (unskilled) workers in the monopoly state, and decreases (increases) the wage and utility of skilled (unskilled) workers in the competition state.

Proof: See the appendix.

Proposition 2 shows that the introduction of a small amount of redistribution raises the wage rate of each type of worker in one state of the world and 
lowers it in the other state. For tax rates close to zero, the general equilibrium wage effect dominates the direct effect of income transfers in the utility calculation. Together, propositions 1 and 2 highlight the impacts of small amounts of redistribution on the equilibrium number of researchers and on wages and static utility. These forces play an important role in determining social welfare, but they are not the full story. As the amount of redistribution is increased the direct effects of net fiscal transfers become relatively more important. Furthermore, the intertemporal spillover effect becomes crucial in calculating the present value of the stream of social welfare.

\section{Social Welfare}

Define the productivity-adjusted utilities for the three types of workers as, $u_{e}^{\phi}$, $u_{m}^{\phi}$, and $u_{u}^{\phi}$, where $u_{i}^{\phi} \equiv U_{i t}^{\phi} / A_{t}^{\alpha}$, with $i=e, m, u$. The steady state flow of utilitarian social welfare in a given period $t$ with a market structure $\phi \in\{0,1\}$ is then

$$
W_{t}^{\phi}=A_{t}^{\alpha}\left(R^{\phi} u_{e}^{\phi}+M^{\phi} u_{m}^{\phi}+L u_{u}^{\phi}\right) .
$$

All the terms in (24) are time-invariant except the technology index $A_{t}$, which increases by a factor $\gamma$ with each innovation. By arbitrage $u_{e}^{\phi}=u_{m}^{\phi}$, and therefore the flow of welfare can be written succinctly as, $W_{t}^{\phi}=A_{t}^{\alpha} u^{\phi}$, where $u^{\phi} \equiv H u_{e}^{\phi}+L u_{u}^{\phi}$.

In order to calculate expected social welfare, we need to consider the branching process for innovations arising from the state-dependent Markov chain defined by the transition probabilities $q^{0}$ and $q^{1}$. Suppose we start at a particular initial state at time 0 , say, $\phi_{0}=1$, for which the total utility flow in period 0 is $u^{1}$. In period 1 , there are two possibilities: with probability $q^{1}$ an innovation occurs, in which case (undiscounted) utility is $\gamma u^{1}$, or with probability $1-q^{1}$ no innovation occurs, for which utility is $u^{0}$. Similarly, in period 2, there are four possible branches, generating an expected utility flow of $\left(q^{1}\right)^{2} \gamma^{2} u^{1}+q^{1}\left(1-q^{1}\right) \gamma u^{0}+\left(1-q^{1}\right) q^{0} \gamma u^{1}+\left(1-q^{1}\right)\left(1-q^{0}\right) u^{0}$. And so on for $t$ periods.

An undesirable feature of the above welfare calculation is that period $t$ probabilities of success or failure depend on the specific initial state. This type of bias can be eliminated using the steady state probabilities of the Markov process given by $q$ and $1-q$ in (22). In this case, letting $\delta$ denote the social discount rate, we have the following.

Lemma 2 The discounted expected social welfare over an infinite horizon $W$ is finite if $\delta<1 / \gamma$ and is given by

$$
\begin{aligned}
W= & q u^{1}+(1-q) u^{0} \\
& +\sum_{t=1}^{\infty} \delta^{t} \sum_{s=0}^{t}\left(\begin{array}{c}
t ! \\
s !(t-s) !
\end{array}\right) q^{s}(1-q)^{t-s} \gamma^{s}\left[\frac{s u^{1}+(t-s) u^{0}}{t}\right] .
\end{aligned}
$$


Proof: See appendix.

To better understand the different effects of taxation on social welfare, we derive a second-order Taylor series approximation of $W$.

Lemma $3 A$ Taylor series expansion for $W$ around the expected value of $s$, $E(s)=t q$, yields an approximate welfare function of the form

$$
W \approx \frac{\left(q u^{1}+(1-q) u^{0}\right)+\delta \gamma^{q} q(1-q) \ln \gamma\left[\frac{q u^{1}+(1-q) u^{0}}{2\left(1-\delta \gamma^{q}\right)} \ln \gamma-\left(u^{0}-u^{1}\right)\right]}{1-\delta \gamma^{q}} .
$$

Proof: See appendix.

This expression has an intuitive interpretation. To understand it, recall that $q$ represents both the probability of being in a monopoly state, as well as the probability of an innovation, and we should in fact think of these as two unrelated events. The first term in the numerator of $(26)$ is simply the expected static utility, from period 0 onwards, that would prevail if there were no technological change. The second term captures the gains and losses from innovation, discounted from period 1 onwards. Every time there is an innovation, the economy becomes a copy of its previous situation but scaled up by a factor of $\ln \gamma$; while $q(1-q)$ is simply the variance of the innovation process. The term in square brackets are the benefit minus the cost of innovating: an innovation increases expected static utility by a factor of $\ln \gamma$ permanently (hence the discount factor in the denominator of the first term in square brackets), and has a cost in terms of lost utility in the period following the innovation (as there is monopoly rather than competition), captured by $\left(u^{0}-u^{1}\right){ }^{12}$

Differentiating (26) with respect to $q$ we can see that the sign of the derivative is ambiguous. The benefits of intertemporal spillovers are set against the loss of (potential) output occurring when the economy moves from a competition state to a monopoly state, which is similar to the 'business stealing' effect that results in excessive growth in Aghion and Howitt (1992). In both case, it can be optimal for the social planner to reduce growth.

\section{Optimal Tax Rates}

As is clear from the previous section, there a number of effects working in opposite directions, that make it impossible to obtain analytically the optimal tax rates. In this section, numerical examples are used to show the implications of the model for optimal tax rates, growth, and long-run expected social welfare.

The baseline parameter values are shown in table 1 . It is important to emphasize that the model is highly stylized, hence the examples we present are not intended to replicate growth rates, research employment, or any other feature of an actual economy. In general, they concern variables that are difficult or impossible to measure empirically (the probability of a research success, the

\footnotetext{
${ }^{12}$ The numerical simulations show the Taylor series expansion of the welfare function provides a very good approximation.
} 
magnitude of the quality improvement, etc.), hence our choices have been arbitrary.

Table 1: Baseline parameters

\begin{tabular}{|l|l|l|}
\hline Production technology & $\theta=0.5$ & $\gamma=1.5$ \\
\hline Research technology & $\lambda=0.3$ & $\eta=0.25$ \\
\hline Preferences & $\alpha=0.75$ & $\delta=0.25$ \\
\hline Population & $H=20$ & $L=40$ \\
\hline Simulation periods & 100 & \\
\hline
\end{tabular}

The model is simulated for the baseline parameter values in table 2 , while in each of tables 3 to 6 a single parameter is varied relative to the baseline. The headings $E u_{u}$ and $E u_{e}$ represent the expected utilities of unskilled and skilled workers respectively. The term $\Delta W$ is the change in the discounted value of social welfare, relative to the laissez-faire equilibrium. The tables report the optimal unconstrained and the optimal constrained (i.e. $\tau^{0}=\tau^{1}$ ) tax rates. The effects of introducing small tax rates are also reported in table 2 to illustrate propositions 1 and 2. In the baseline case, the laissez-faire economy exhibits a moderate research activity in competition periods and a large research sector in monopoly periods, with about 12 and 23 per cent of the skilled labor force engaged in research, respectively. The growth rate has been annualized, under the assumption that each period - which represents the lifetime of a research project - corresponds to 7 years. Our example implies an annual expected growth rate of 2.18 per cent. The expected utility of skilled workers is 64 per cent higher than that of unskilled workers.

We can infer several interesting results from the simulations.

1. Optimal tax rates are high.

The optimal values of $\tau^{0}$ and $\tau^{1}$ lie between 33 and 80 per cent. One reason for this is that uncertainty generates a substantial utility loss that the social planner wants to neutralize by providing insurance. This finding is similar to Eaton and Rosen's (1980) demonstration that, even if the fraction of the population that experiences wage uncertainty is small, optimal tax rates are high.

2. Growth-promotion is achieved primarily with redistribution in the competition state (using $\tau^{0}$ ), while income-equalization is achieved primarily with redistribution in the monopoly state (using $\tau^{1}$ ). 
Table 2: Baseline case

\begin{tabular}{|c|c|c|c|c|c|c|c|c|}
\hline \multirow{6}{*}{$\begin{array}{l}H=20 \\
L=40\end{array}$} & $\tau^{1}$ & $\tau^{0}$ & $R^{1}$ & $R^{0}$ & $g$ & $E u_{u}$ & $E u_{e}$ & $\Delta W$ \\
\hline & $\overline{0}$ & $\overline{0}$ & 4.63 & 2.47 & 2.18 & .487 & .760 & - \\
\hline & .05 & 0 & 4.98 & 2.33 & 2.18 & .489 & .761 & 0.26 \\
\hline & 0 & .05 & 4.63 & 2.73 & 2.20 & .490 & .754 & 0.07 \\
\hline & .64 & .64 & 6.63 & 3.27 & 2.35 & .549 & .661 & 2.34 \\
\hline & .69 & .57 & 6.79 & 2.27 & 2.27 & .550 & .669 & 2.50 \\
\hline \multirow{5}{*}{$\begin{array}{c}H=25 \\
L=40\end{array}$} & 0 & 0 & 5.79 & 3.09 & 2.30 & .533 & .696 & - \\
\hline & .05 & 0 & 6.22 & 2.91 & 2.31 & .534 & .699 & 0.28 \\
\hline & 0 & .05 & 5.79 & 3.44 & 2.34 & .535 & .693 & 0.06 \\
\hline & .61 & .61 & 8.38 & 4.15 & 2.51 & .573 & .651 & 2.14 \\
\hline & .65 & 53. & 8.55 & 2.97 & 2.41 & .573 & .658 & 2.28 \\
\hline \multirow{5}{*}{$\begin{aligned} H & =15 \\
L & =40\end{aligned}$} & 0 & 0 & 3.47 & 1.85 & 2.03 & .434 & .851 & - \\
\hline & .05 & 0 & 3.67 & 1.75 & 2.02 & .437 & .849 & 0.26 \\
\hline & 0 & .05 & 3.47 & 2.03 & 2.06 & .437 & .842 & 0.11 \\
\hline & .70 & .70 & 4.93 & 2.42 & 2.19 & .521 & .660 & 2.94 \\
\hline & .73 & .63 & 5.01 & 1.70 & 2.09 & .521 & .674 & 3.14 \\
\hline
\end{tabular}

Comparing the second and third lines of each panel in table 2, we can see that the two taxes have different effects on innovation and redistribution. $\tau^{0}$ has a strong growth effect, as it implies that producers are subsidizing unsuccessful entrepreneurs, hence providing insurance and encouraging innovation. On the contrary, $\tau^{1}$ has a large redistributive effect as it taxes the (very rich) patent holder and redistributes the proceeds, strongly impacting welfare. However, it reduces the prize obtained by a successful researcher, partially offsetting the insurance effect on innovation.

To highlight the importance of considering entrepreneurship in a dynamic context, table 3 shows the equilibrium with no growth $(\gamma=1)$; entrepreneurship is then a purely rent-seeking activity with no social benefit. Comparing these results with those of table 2 we see that the optimal tax rates are substantially lower in the absence of technical change. The social planner is only interested in reducing inequality, and has no reason to want to promote entrepreneurship as all it does is transfer monopoly profits from one individual to another. It is particularly striking that the optimal value of $\tau^{0}$ is zero. Since the main role of $\tau^{0}$ is to provide insurance and encourage research, the social planner minimizes the loss due to rent-seeking by providing no insurance.

These considerations explain the effects of varying the discount factor in table 4 . With high discounting, $\delta=0.1$, the social planner cares strongly about redistribution and chooses a high tax on profits that entails a substantial amount of redistribution and hence a large increase in welfare. With low discounting, $\delta=0.5$, the planner cares strongly about growth, and provides a substantial amount of insurance (high $\tau^{0}$ ) in order to promote growth. For an intermediate value of $\delta$ the planner faces a trade-off between the static redistributive gains 
and the dynamic benefits, and the resulting compromise in tax rates leads to a small improvement in welfare.

Table 3: No growth case

\begin{tabular}{|c|cccccccc|}
\hline & $\tau^{1}$ & $\tau^{0}$ & $R^{1}$ & $R^{0}$ & $g$ & $E u_{u}$ & $E u_{e}$ & $\Delta W$ \\
\hline \hline$\gamma=1$ & 0 & 0 & 3.34 & 1.75 & 0 & .437 & .685 & - \\
$\eta=0.25$ & .58 & .58 & 4.80 & 2.26 & 0 & .489 & .599 & 1.14 \\
& .42 & 0 & 4.45 & 1.00 & 0 & .453 & .690 & 2.35 \\
\hline
\end{tabular}

Table 4: Different discount rates

\begin{tabular}{|c|cccccccc|}
\hline \multicolumn{10}{c|}{} & $\tau^{1}$ & $\tau^{0}$ & $R^{1}$ & $R^{0}$ & $g$ & $E u_{u}$ & $E u_{e}$ & $\Delta W$ \\
\hline \hline$\delta=0.1$ & 0 & 0 & 4.63 & 2.47 & 2.18 & .487 & .760 & - \\
& .56 & .56 & 8.19 & 4.06 & 2.49 & .570 & .656 & 13.48 \\
& .65 & .33 & 8.55 & 1.90 & 2.27 & .566 & .675 & 14.11 \\
\hline$\delta=0.25$ & 0 & 0 & 4.63 & 2.47 & 2.18 & .487 & .760 & - \\
& .64 & .64 & 6.63 & 3.27 & 2.35 & .549 & .661 & 2.34 \\
& .69 & .57 & 6.79 & 2.27 & 2.27 & .550 & .669 & 2.50 \\
\hline$\delta=0.5$ & 0 & 0 & 4.63 & 2.47 & 2.18 & .487 & .760 & - \\
& .80 & .80 & 7.23 & 3.56 & 2.40 & .562 & .623 & 4.56 \\
& .77 & .85 & 7.10 & 5.57 & 2.54 & .554 & .615 & 5.03 \\
\hline
\end{tabular}

Table 5: Degrees of monopoly power

\begin{tabular}{|c|cccccccc|}
\hline & $\tau^{1}$ & $\tau^{0}$ & $R^{1}$ & $R^{0}$ & $g$ & $E u_{u}$ & $E u_{e}$ & $\Delta W$ \\
\hline \hline$\theta=0.4$ & 0 & 0 & 6.22 & 2.84 & 1.72 & .589 & .6586 & - \\
& .55 & .55 & 8.54 & 3.66 & 2.47 & .600 & .650 & 1.52 \\
& .59 & .44 & 8.68 & 2.58 & 2.37 & .600 & .6589 & 1.64 \\
\hline$\theta=0.5$ & 0 & 0 & 4.63 & 2.47 & 2.18 & .487 & .760 & - \\
& .64 & .64 & 6.63 & 3.27 & 2.35 & .549 & .661 & 2.34 \\
& .69 & .57 & 6.79 & 2.27 & 2.27 & .550 & .669 & 2.50 \\
\hline$\theta=0.6$ & 0 & 0 & 3.34 & 2.07 & 2.05 & .392 & .849 & - \\
& .73 & .73 & 4.98 & 2.84 & 2.24 & .561 & .649 & 3.90 \\
& .76 & .68 & 5.08 & 2.04 & 2.14 & .561 & .657 & 4.06 \\
\hline
\end{tabular}

3. Optimal redistribution can result in a Pareto improvement.

All generations are better off if redistribution raises the growth rate and simultaneously increases the steady state expected utilities of skilled and un- 
skilled workers. ${ }^{13}$ An example of a Pareto-improving optimal redistribution is shown in table $5(\theta=0.4)$, where there is a high degree of monopoly power. In this case the losses associated with monopoly are large and, consequently, the optimal tax rates are relatively small. The direct effect on skilled incomes is modest and offset by the increase in wages, leaving the skilled marginally better off, while the unskilled are significantly better off due to the redistribution of income.

4. Welfare gains can be large.

In our baseline example, welfare gains from optimal taxation are moderate, between 2.3 and 3.1 per cent. Tables 4 and 5 show that gains can be large, of up to 14 per cent.

\section{Optimal redistribution can be growth-enhancing.}

This is the case in all the examples in the tables. The impact of optimal redistribution on growth depends heavily on the social planner's discount rate. In the baseline case (table 2, panel 1, row 5) the effect of redistribution on growth is moderate, raising the annual growth rate by only 0.09 percentage points. However, with a high discount rate (e.g., $\delta=0.5$ in table 4 ) or a high degree of monopoly power (e.g., $\theta=0.4$ in table 6 ), the effect is much stronger, increasing the growth rate by 0.4 to 0.6 of a percentage point. On the other hand, redistribution may also reduce growth, as can be seen in the third panel of table 2, where the number of skilled workers is small and only a small (nonoptimal) tax rate of $\tau^{1}=0.05$ is applied.

6. There is a tradeoff between social welfare and growth, which depends on the size of the intertemporal spillover.

In almost all the cases shown in the tables, the growth rate is higher when taxes are constrained to be the same in both states than when they are set at the unconstrained optimum. The static and dynamic consequences of innovation have opposite effects on social welfare, hence $W$ is not necessarily increasing in $q$. The size of intertemporal spillovers, determined by $\gamma$, is crucial for optimizing this tradeoff. From lemma 1 we know that greater spillovers lead to higher values of $q$, which in turn affect the balance between static and dynamic social welfare considerations. The dynamic effect of $\gamma$ is simply that the greater the spillover, the larger the increase in output following an innovation. Innovation hence creates a large social surplus and the social planner would tend to use redistributive taxation to foster research activity. There are two static effects.

\footnotetext{
${ }^{13}$ The expectations of workers are taken with respect to aggregate risk; e.g., $E U_{m}=q U_{m}^{1}+$ $(1-q) U_{m}^{0}$ is the expected utility of producers. Note also that the first term in the social welfare function (26) can be written as the sum of the expected utilities of skilled and unskilled workers:

$$
q u^{1}+(1-q) u^{0}=H\left(q u_{m}^{1}+(1-q) u_{m}^{0}\right)+L\left(q u_{u}^{1}+(1-q) u_{u}^{0}\right) .
$$
}


First, a larger $\gamma$ results in a larger $q$, hence monopoly states and their consequent output loss occur more frequently. Second, the larger is $\gamma$, the higher $R^{\phi}$ and the lower $M^{\phi}$ are. As a result, the ratio of skilled to unskilled wages is larger, i.e. inequality is greater. ${ }^{14}$

Now consider the social welfare function (26). Suppose $\gamma$ is close to one. Then the dynamic component of social welfare drops out. Moreover, there is little incentive to innovate when $\gamma$ is small, so $q$ will be small. Optimal taxation will be driven, in this case, mainly by the desire to maximize $u^{0}$. Since skilledunskilled inequality rises with $\gamma$, optimal tax rates will be increasing in $\gamma$ when the spillover is small. Moreover, when growth is moderate the government will want to encourage entrepreneurship through redistribution. However, as $\gamma$-and hence $q$-increase the welfare loss due to monopoly power becomes progressively larger. The social planner does not want to encourage excessive growth, and the optimal tax rate eventually falls. The reduction in the tax rate is, however, partly offset by the fact that a high $\gamma$ also increases inequality, thus calling for more redistribution. These considerations suggest our final result.

7. Optimal tax rates are hump-shaped functions of the spillover factor.

Figure 2 depicts the constrained optimal tax rates -i.e., $\tau^{1}=\tau^{*}=\tau^{0}$ —as they relate to $\gamma$. As $\gamma$ increases the optimal tax rate rises rapidly, attaining its maximum for $\gamma=1.5$, and then falling slowly because of the trade-off between the efficiency and equity considerations. Note that the constrained optimal tax rates always lie between the optimal unconstrained values of $\tau^{0}$ and $\tau^{1}$ in the tables. The hump-shaped profile depicted in figure 2 is similar to both of the optimal unconstrained tax rate profiles.

\footnotetext{
${ }^{14}$ It is straightforward to verify that $\gamma$ does not affect the ratio of skilled wages to monopoly profits.
} 
Figure 2

Spillovers and optimal tax rates

Spillovers and the optimal tax rate

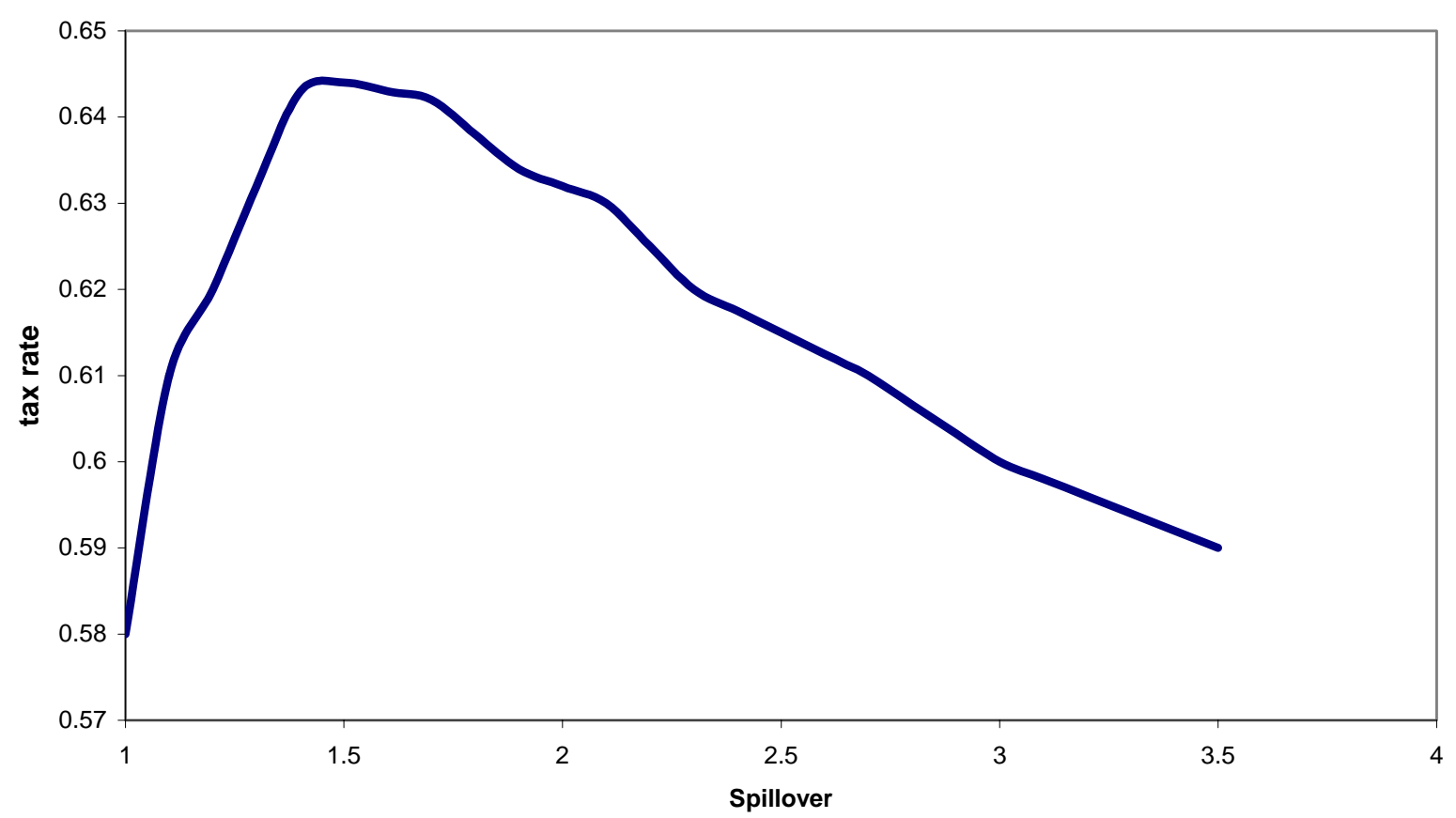

For $1<\gamma \leq 1.5$, the optimal tax rate stimulates the growth rate relative to the laissez-faire equilibrium ; for $\gamma>1.5$, the optimal tax reduces growth. 


\section{Conclusions}

We have examined the effect of redistribution in an R\&D-driven growth model, where the occupational choice between production and risky entrepreneurship determines the rate of innovation and growth. The paper brings together two strands of literature, the endogenous growth literature and the analysis of taxation and occupational choice, which had not previously been combined. Its contribution is twofold. On the one hand, we have explicitly examined what was a neglected implication of the Schumpeterian growth model, that because redistribution acts as social insurance, it can increase the incentives for individuals to undertake risky $\mathrm{R} \& \mathrm{D}$. With sufficient risk aversion this effect is strong enough to offset the standard effects of taxation through the reduction of profits and hence result in a faster growth rate. On the other, we have embedded some of the existing results of the optimal taxation literature in a general equilibrium model. This implies, first, that the market incomes of different individuals are endogenous and hence affected by the tax choices. Second, the degree of uncertainty in the economy becomes endogenous, as the aggregate effect of occupational choices affects the probability of success of individual entrepreneurs. This consideration, in combination with the technological spillovers from innovation, generates an externality that is taken into account by the social planner when choosing the optimal tax rates. We show that optimal tax rates are a hump-shaped function of the size of the intertemporal spillover from innovation.

An important aspect of our analysis is that we have assumed finite lives. A large part of the literature on taxation and growth focuses on infinitely-lived agents. In this case, policies that increase the growth rate tend to also increase the welfare of all individuals, since the dynamic effect of faster growth offsets static losses. Our approach, in contrast, has examined the welfare gains and losses of short-lived agents, and shown that even in this case general equilibrium effects may be powerful enough to offset direct redistributive losses to the richest individuals and generate a Pareto improvement, raising the welfare of all individuals.

Our analysis has considered cash redistribution as the only possible policy that the government can undertake. However, an important and well-known implication of the type of model we analyze is that R\&D subsidies can affect the growth rate. Such subsidies have, however, been the object of substantial criticism from economists, because of the scope for diversion of expenditures and manipulation to which they are subject (Katz and Ordover, 1990). This manipulation can take place at the firm level, or even at the level of the government which can use them in order to engage in tax competition with other countries and attract enterprises. By focussing on redistribution we are not arguing that R\&D subsidies should not be used, rather we have provided a possible alternative policy to foster growth, which could be used when R\&D subsidies are deemed problematic.

We have focused on linear income redistribution, but it is noteworthy that even lump-sum transfers generally do not produce optimality, when entrepreneur- 
ship is an occupational choice. Even in the simplest models the first-best optimum requires the coordinated use of several policies, such as occupational licensing, price controls, and either wage controls or redistribution (Kanbur, 1981). Thus any single policy measure produces at most a second-best op-

timum. Finally, redistributions provided in-kind, such as free schooling and public health care, may be just as important as cash transfers in reality for an entrepreneur evaluating the possible consequences of taking risks.

\section{References}

Aghion, Philippe and Patrick Bolton (1997) A Trickle-Down Theory of Growth and Development with Debt Overhang, Review of Economic Studies, 64:2, pp. $151-62$.

Aghion, Philippe, Eve Caroli, and Cecilia García-Peñalosa (1999) Inequality and Growth in the New Growth Theories, Journal of Economic Literature, 37, pp. 1615-69.

Aghion, Philippe, and Howitt, Peter (1992) A Model of Growth Through Creative Destruction, Econometrica, vol. 60, pp. 323-51.

Aghion, Philippe and Peter Howitt (1998) Endogenous Growth Theory. Cambridge: MIT Press.

Bird, Edward J. (2001) Does the Welfare State Induce Risk-Taking? Journal of Public Economics 80: 357-383.

Boadway, R. Marchand, M. and P. Pestieau (1991) Optimal Linear Income Taxation in Models with Occupational Choice, Journal of Public Economics, 46:2, pp. 133-62.

Bruce, D. (2000) The Effects of the United States Tax System on Transitions into Self-Employment, Labour Economics 7, 545-574.

Caucutt, Elizabeth M., K.B. Kumar, and S. Imrohoroglu (2003) Growth and Welfare Analysis of Tax Progressivity in a Heterogeneous Agent Model, Review of Economic Dynamics 6: 546-577.

Chou, Chien-fu and Gabriel Talmain (1996). Redistribution and Growth: Pareto Improvements, Journal of Economic Growth, 1(4): 505-23.

Cooper, Arnold C., Woo, Carolyn Y. and William C Dunkelberg (1988) Entrepreneurs' Perceived Chances for Success, Journal of Business Venturing 3(2), 97-108.

Cooper, Ben, Cecilia García-Peñalosa, and Peter Funk (2001) Status Effects and Negative Utility Growth, Economic Journal, vol. 111, pp. 642-665.

Dunne, Timothy, Roberts, Mark J., and Larry Samuelson (1988) Patterns of Firm Entry and Exit in US Manufacturing Industries, RAND Journal of Economics 19(4), 495-515.

Eaton, Jonathan, and Harvey S. Rosen (1980) Optimal Redistributive Taxation and Uncertainty, Quarterly Journal of Economics, 357-364.

Feller, William (1968) An Introduction to Probability Theory and its Applications: Volume I, third edition, revised printing. (New York: John Wiley \& Sons). 
Galor, Oded and Joseph Zeira (1993) Income Distribution and Macroeconomics, Review of Economic Studies, 60(1): 35-52.

Gentry, W. and R.G. Hubbard (2000) Tax Policy and Entrepreneurial Entry, American Economic Review, 90, 283-287.

Gentry, William M. and Glenn R. Hubbard (2001a) Entrepreneurship and Household Saving, NBER (Cambridge, MA) Working Paper No. 7894.

Gould, Eric, Omer Moav and Bruce A. Weinberg (2001) Precautionary Demand for Education, Inequality, and Technological Progress, Journal of Economic Growth 6(4), 285-315.

Hamilton, Barton H. (2000) Does Entrepreneurship Pay? An Empirical Analysis of the Returns to Self-Employment, Journal of Political Economy 108(3), 604-31.

Kanbur, S.M. (1981) Risk Taking and Taxation: An Alternative Perspective, Journal of Public Economics, 15:2, pp. 163-84.

Katz, M. and J. Ordover (1990) R\&D Cooperation and Competition, Brookings Papers, Microeconomics, 137-203.

Lambson, Val E. and Kerk L. Phillips (2004) Market Structure and Schumpeterian Growth, mimeo.

Moskowitz, Tobias and Annette Vissing-Jorgensen (2002) The Returns to Entrepreneurial Investment: A Private Equity Premium Puzzle, American Economic Review 92(4), 745-778.

Peck, Richard M. (1989) Taxation, Risk, and Returns to Scale, Journal of Public Economics 40: 319-330.

Saint-Paul, Gilles and Thierry Verdier (1996). Inequality, Redistribution and Growth : A Challenge to the Conventional Political Economy Approach, European Economic Review, 40 (3-5):719-28

Varian, Hal R. (1980) Redistributive Taxation as Social Insurance, Journal of Public Economics 14, 49-68. 


\section{Appendix}

\subsection{The Long-Run Probability of Innovation}

Given the equilibrium number of researchers, the probabilities of innovation in each period follow a state-dependent Markov chain with a matrix of transitions $Q$ given by

$$
Q=\left(\begin{array}{ll}
q^{1} & 1-q^{1} \\
q^{0} & 1-q^{0}
\end{array}\right)
$$

where $q^{1} \equiv \lambda\left(R^{1}\right)^{\eta}$ and $q^{0} \equiv \lambda\left(R^{0}\right)^{\eta}$ are the probabilities of innovation in the current period when the current state is $\phi=1$ and $\phi=0$, respectively. Similarly, $1-q^{1}$ and $1-q^{0}$ are the probabilities of no innovation given the current state.

Given an initial state at time $0, \phi_{0} \in\{1,0\}$, the probability of an innovation occurring in some future period $t$ is determined by a power matrix defined as

$$
Q(t) \equiv\left(\begin{array}{cc}
q^{1}(t) & 1-q^{1}(t) \\
q^{0}(t) & 1-q^{0}(t)
\end{array}\right)
$$

where $Q(t) \equiv Q \times Q \times \ldots \times Q \quad(t$ times $)$. For instance, if $\phi_{0}=1$, then the probability of an innovation occurring in period 2 is $q^{1}(2)=\left(q^{1}\right)^{2}+\left(1-q^{1}\right) q^{0}$, while if $\phi_{0}=0$, then $q^{0}(2)=q^{0} q^{1}+\left(1-q^{0}\right) q^{0}$.

It is well known that as $t$ increases the importance of the initial state $\phi_{0}$ in determining the future probabilities vanishes; that is, in the limit $q^{1}(t)=q^{0}(t)$. Letting $q$ denote this steady state probability of innovation, the solution for $q$ (see, e.g., Feller, 1968) is

$$
\begin{aligned}
q & =\frac{q^{0}}{1-q^{1}+q^{0}}, \\
1-q & =\frac{1-q^{1}}{1-q^{1}+q^{0}} .
\end{aligned}
$$

Thus in the long run the state-dependent Markov process converges to an invariant probability distribution, generating a simple Bernouilli process for innovation, in which at any future period $t$ there is a chance $q$ that an innovation occurs, regardless of the initial state $\phi_{0}$.

\subsection{Proofs}

Proof of Proposition 1. From the equilibrium equation (17) it is immediately seen that the introduction of a $\operatorname{tax} \tau^{0}$ does not affect research in the monopoly state. Totally differentiating (18), using (20) to substitute for $\left(\frac{H-R^{1}}{H-R^{0}}\right)^{\theta}$, and evaluating the derivative at $\tau^{0}=0$, yields $\frac{d R^{0}}{d \tau^{0}}=\infty$. Hence, the introduction of a tax $\tau^{0}$ increases $R^{0}$ and the probability of innovation in the competition state 
$q_{0}$. Recall that the growth rate is given by $g=q \ln \gamma$, where $q$ is increasing in $q_{0}$. Then $d g / d \tau^{0}>0$.

Consider now the effect of $\tau^{1}$. Totally differentiating (17) and letting $\tau^{1}=0$ we obtain,

$$
\begin{aligned}
& {\left[\alpha \frac{\theta^{2 \alpha}}{\left(H-R^{1}\right)^{1+\alpha}}+\lambda(1-\eta)\left(R^{1}\right)^{\eta-2}(1-\theta)^{\alpha} \theta^{\alpha} \gamma^{\alpha}\right] \frac{d R^{1}}{d \tau^{1}} } \\
= & {\left[\lambda\left(R^{1}\right)^{\eta-1} \alpha \frac{\left(\frac{1}{N}-(1-\theta) \theta \gamma\right)}{((1-\theta) \theta \gamma)^{1-\alpha}}+\alpha\left(1-\lambda\left(R^{1}\right)^{\eta-1}\right) \frac{1}{N^{\alpha}} \frac{1}{\left(\tau^{1}\right)^{1-\alpha}}-\alpha \frac{\left(\frac{1}{N}-\frac{\theta^{2}}{H-R^{1}}\right)}{\left(\frac{\theta^{2}}{H-R^{1}}\right)^{1-\alpha}}\right] }
\end{aligned}
$$

The term $1 /\left(\tau^{1}\right)^{1-\alpha}$ on the RHS of (A5) approaches infinity as $\tau^{1}$ goes to zero, while all other terms are finite; therefore, $d R^{1} / d \tau^{1}=\infty$ at $\tau^{1}=0$.

The effect of $\tau^{1}$ on $R^{0}$ is more complicated as $R^{0}$ depends on $R^{1}$ as well as on $\tau^{1}$. Differentiating (18) and setting $\tau^{1}=0=\tau^{0}$ gives

$$
\begin{aligned}
& \lambda(\eta-1)\left(R^{0}\right)^{\eta-2}\left((1-\theta) \theta \gamma \frac{y^{1}}{y^{0}}\right)^{\alpha} d R^{0} \\
& +\lambda\left(R^{0}\right)^{\eta-1} \alpha \frac{(-1)(1-\theta) \theta \gamma\left(\frac{y^{1}}{y^{0}}\right)+(1-\theta) \theta \gamma \frac{d\left(\left(\frac{H-R^{1}}{H-R^{0}}\right)^{\theta}\right)}{d \tau^{1}}}{\left((1-\theta) \theta \gamma \frac{y^{1}}{y^{0}}\right)^{1-\alpha}} d \tau^{1} \\
& =\alpha\left(\frac{\theta}{H-R^{0}}\right)^{\alpha-1} \theta \frac{d R^{0}}{\left(H-R^{0}\right)^{2}}
\end{aligned}
$$

where

$$
\frac{d\left(\left(\frac{H-R^{1}}{H-R^{0}}\right)^{\theta}\right)}{d \tau^{1}}=\theta\left(\frac{y^{1}}{y^{0}}\right)\left(\frac{1}{H-R^{0}} \frac{d R^{0}}{d \tau^{1}}-\frac{1}{H-R^{1}} \frac{d R^{1}}{d \tau^{1}}\right) .
$$

By manipulating (20), we can write

$$
\left(\frac{y^{0}}{y^{1}}\right)^{\alpha}=\left(\frac{H-R^{0}}{H-R^{1}}\right)^{\alpha \theta}=\left(\frac{H-R^{0}}{\left(R^{0}\right)^{(1-\eta) / \alpha}}\right)^{\alpha} \gamma^{\alpha} \lambda(1-\theta)^{\alpha} .
$$

Substituting (A7) and the reciprocal of (A8) into (A6) gives

$$
\begin{array}{r}
\frac{d R^{0}}{d \tau^{1}}=-\frac{\alpha R^{0}\left(H-R^{1}\right)}{(1-\eta)\left(H-R^{0}\right)+(1-\theta) \alpha R^{0}}\left(\frac{H-R^{0}}{H-R^{1}}\right) \\
-\frac{\alpha \theta R^{0}}{(1-\eta)\left(H-R^{0}\right)+(1-\theta) \alpha R^{0}}\left(\frac{H-R^{0}}{H-R^{1}}\right) \frac{d R^{1}}{d \tau^{1}} .
\end{array}
$$


In the limit, as $\tau^{1}$ approaches zero, $d R^{1} / d \tau^{1}$ approaches infinity, and therefore, $d R^{0} / d \tau^{1}=-\infty$ in (27).

The growth rate is given by $g=q \ln \gamma$. Recall that $q=q^{0} /\left(1-q^{1}+q^{0}\right)$, implying that the tax has opposing effects on the two probabilities of innovation. Differentiating $q$ with respect to the tax rate we have

$$
\frac{d q}{d \tau^{1}}=\lambda \eta\left[\frac{\left(1-q^{1}\right)}{\left(R^{0}\right)^{1-\eta}} \frac{d R^{0}}{d \tau^{1}}+\frac{q^{0}}{\left(R^{1}\right)^{1-\eta}} \frac{d R^{1}}{d \tau^{1}}\right] /\left(1-q^{1}+q^{0}\right)^{2} .
$$

The sign of $d q / d \tau^{1}$ depends on the sign of the term in brackets. Substituting for $d R^{0} / d \tau^{1}$ using (A9), and for $d R^{1} / d \tau^{1}$ using (A5), and rearranging terms, shows that $d q / d \tau^{1}>0$ if and only if

$$
\frac{q^{1}}{1-q^{1}}>\frac{\frac{\alpha \theta}{\left(H / R^{1}-1\right)}}{(1-\eta)+\frac{\alpha(1-\theta)}{\left(H / R^{0}-1\right)}} .
$$

This expression can be shown to be satisfied for $H$ sufficiently large. On the right-hand side of (A11), the minimum value of the denominator equals $1-\eta$. Now consider its numerator. From (19), write the solution for $R^{1}$ implicitly as,

$$
R^{1}+\psi\left(R^{1}\right)^{(1-\eta) / \alpha}=H,
$$

where $\psi=\left(1 / \gamma \lambda^{1 / \alpha}\right)(\theta /(1-\theta))$ is a constant. Differentiating this expression gives,

$$
\frac{d R^{1}}{d H}\left(1+\psi \frac{(1-\eta)}{\alpha}\left(R^{1}\right)^{(1-\eta-\alpha) / \alpha}\right)=1
$$

implying that $0<d R^{1} / d H<1$. Therefore as $H$ rises, $R^{1}$ does not rise by as much. Thus $H / R^{1}$ must rise with $H$ and the right-hand side of (A11) goes to zero. The the left-hand side of (A11) is increasing in $H$, as $d\left(q^{1} /\left(1-q^{1}\right)\right) / d q^{1}>$ $0, d q^{1} / d R^{1}>0$, and $d R^{1} / d H>0$. Hence, for $H$ sufficiently large, (A11) is satisfied. The reasoning above is for an interior solution $(q<1)$. If, instead, a corner solution is reached, then (A11) is satisfied trivially.

Proof of Proposition 2. For the effect of taxes on equilibrium wages, totally differentiate (4)-(8) with respect to $\tau^{0}$ and $\tau^{1}$, using (2) and (1) to substitute for $Y^{\phi}$ in terms of $M^{\phi}=H-R^{\phi}$. The signs of the wage derivatives then follow immediately by applying proposition 1 to $d R^{\phi} / d \tau^{0}$ and $d R^{\phi} / d \tau^{1}$.

For the effect of taxes on the equilibrium utilities of skilled workers, totally 
differentiate (13) and rearrange terms to obtain

$$
\begin{aligned}
\frac{d U_{m}^{1}}{d \tau^{1}} & =\alpha \frac{\left(Y^{1}\right)^{\alpha}}{M^{1}}\left(\frac{\theta^{2}}{M^{1}}\right)^{\alpha}\left[(1-\theta) \frac{d R^{1}}{d \tau^{1}}-M^{1}\left(1-\frac{M^{1}}{N \theta^{2}}\right)\right] \\
\frac{d U_{m}^{0}}{d \tau^{1}} & =\alpha \frac{\left(Y^{0}\right)^{\alpha}}{M^{0}}\left(\frac{\theta}{M^{0}}\right)^{\alpha}\left[(1-\theta) \frac{d R^{0}}{d \tau^{1}}-M^{0}\left(1-\frac{M^{0}}{N \theta^{2}}\right)\right] \\
\frac{d U_{m}^{1}}{d \tau^{0}} & =0 \\
\frac{d U_{m}^{0}}{d \tau^{0}} & =\alpha \frac{\left(Y^{0}\right)^{\alpha}}{M^{0}}\left(\frac{\theta}{M^{0}}\right)^{\alpha}\left[(1-\theta) \frac{d R^{0}}{d \tau^{0}}-M^{0}\left(1-\frac{M^{0}}{N \theta^{2}}\right)\right] .
\end{aligned}
$$

Using proposition 1 for the signs of $d R^{\phi} / d \tau^{1}$ and $d R^{\phi} / d \tau^{0}$ determines the signs of the utility derivatives. A similar calculation is applied to the utility of unskilled workers, equation (14), to complete the proof.

Proof of Lemma 2. We calculate social welfare from the long-run probabilities of innovation. The probability that the initial state is $\phi_{0}=1$ can be any value $0 \leq a \leq 1$, but let $a=q$. Thus the first term in the social welfare function is $q u^{1}+(1-q) u^{0}$. The second part of the formula for the social welfare function is obtained by induction from the Bernouilli process with probability $q$ of innovation at each node of the 'tree.' In any period $t$, the number of terms to count is

$$
\sum_{s=0}^{t}\left(\begin{array}{c}
t ! \\
s !(t-s) !
\end{array}\right)=2^{t}
$$

Moreover, the maximum value of the probability term $q^{s}(1-q)^{t-s}$ is $(1 / 2)^{t}$, while $\gamma^{s} \cdot \frac{s u^{1}+(t-s) u^{0}}{t}$ is less than $\gamma^{t} u^{0}$ (since $\max \left\{u^{0}, u^{1}\right\}=u^{0}$ ). Putting these pieces together, yields,

$$
W<\sum_{t=1}^{\infty}(\delta \gamma)^{t} u^{0}
$$

which is finite for $\delta<\gamma$.

Proof of Lemma 3. A second-order approximation can be used to abtain an approximate social welfare function. Denote by $f(s, t)$ the flow of benefits for a given time period $t$, where

$$
f(s, t)=\gamma^{s}\left[\frac{s u^{1}+(t-s) u^{0}}{t}\right] .
$$

The social welfare can then be written as,

$$
W=q u^{1}+(1-q) u^{0}+\sum_{t=1}^{\infty} \delta^{t} E(f(s, t))
$$


where $E(\cdot)$ is the expectation operator under the binomial distribution for a given $t$. Now for a given $t$, take a second-order Taylor series approximation of $f(s, t)$ around the expected value of $s, E(s)=t q$,

$$
f(s, t) \approx f(t q, t)+f^{\prime}(t q, t)(s-t q)+(1 / 2) f^{\prime \prime}(t q, t)(s-t q)^{2}
$$

where $f^{\prime}$ and $f^{\prime \prime}$ are the first and second derivatives of $f$ with respect to $s$. Evaluating $E(f(s, t))$ then gives

$$
E(f(s, t))=f(t q, t)+(1 / 2) f^{\prime \prime}(t q, t) \operatorname{Var}(s)
$$

where $\operatorname{Var}(s)=t q(1-q)$ is the variance of $s$ under the binomial distribution, and

$$
f(t q, t)=\gamma^{t q}\left[q u^{1}+(1-q) u^{0}\right]
$$

is the period- $t$ flow of benefits evaluated at the average number of innovations that have taken place from periods 1 to $t$. We also obtain,

$$
\begin{array}{r}
f^{\prime}(s, t)=\left(\ln \gamma+\frac{u^{1}-u^{0}}{s u^{1}+(t-s) u^{0}}\right) f(s, t) \\
f^{\prime \prime}(s, t)=-\left(\frac{u^{1}-u^{0}}{s u^{1}+(t-s) u^{0}}\right)^{2} f(s, t) \\
+\left(\ln \gamma+\frac{u^{1}-u^{0}}{s u^{1}+(t-s) u^{0}}\right) f^{\prime}(s, t) .
\end{array}
$$

Substituting $f^{\prime}$ into the expression for $f^{\prime \prime}$ gives

$$
f^{\prime \prime}(s, t)=-\left(\frac{u^{1}-u^{0}}{s u^{1}+(t-s) u^{0}}\right)^{2} f(s, t)+\left(\ln \gamma+\frac{u^{1}-u^{0}}{s u^{1}+(t-s) u^{0}}\right)^{2} f(s, t) .
$$

Combining terms and evaluating $f^{\prime \prime}(s, t)$ at $s=t q$ results in the expression,

$$
\begin{array}{r}
f^{\prime \prime}(s, t)=-\gamma^{t q}\left[q u^{1}+(1-q) u^{0}\right]\left(\frac{u^{1}-u^{0}}{t q u^{1}+(t-t q) u^{0}}\right)^{2} \\
+\gamma^{t q}\left[q u^{1}+(1-q) u^{0}\right]\left(\frac{\ln \gamma\left(t q u^{1}+(t-t q) u^{0}\right)}{t q u^{1}+(t-t q) u^{0}}+\frac{u^{1}-u^{0}}{t q u^{1}+(t-t q) u^{0}}\right)^{2}
\end{array}
$$

which simplifies to

$$
f^{\prime \prime}(t q, t)=\gamma^{t q} \ln \gamma\left[\ln \gamma\left(q u^{1}+(1-q) u^{0}\right)+\frac{2}{t}\left(u^{1}-u^{0}\right)\right] .
$$

The approximation to social welfare using the Taylor series expansion for $f(s, t)$ is then given by,

$$
W \approx a u^{1}+(1-a) u^{0}+\sum_{t=1}^{\infty} \delta^{t} E\left[f(t q, t)+(1 / 2) f^{\prime \prime}(t q, t) \operatorname{Var}(s)\right] .
$$


After substituting for $f(t q, t)$ and $f^{\prime \prime}(t q, t)$ using (A19) and (A25), the expression (A26) can be expanded as,

$$
\begin{aligned}
W \approx & a u^{1}+(1-a) u^{0}+\sum_{t=1}^{\infty}\left(\delta \gamma^{q}\right)^{t}\left(q u^{1}+(1-q) u^{0}\right) \\
& (1 / 2) \ln \gamma \sum_{t=1}^{\infty}\left(\delta \gamma^{q}\right)^{t}\left[\ln \gamma\left(q u^{1}+(1-q) u^{0}\right)+\frac{2}{t}\left(u^{1}-u^{0}\right)\right] t q(1-q)
\end{aligned}
$$

which can be written as,

$$
\begin{aligned}
W \approx & a u^{1}+(1-a) u^{0}+\sum_{t=1}^{\infty}\left(\delta \gamma^{q}\right)^{t}\left(q u^{1}+(1-q) u^{0}\right) \\
& +(1 / 2)\left(q u^{1}+(1-q) u^{0}\right) q(1-q)(\ln \gamma)^{2} \sum_{t=1}^{\infty} t\left(\delta \gamma^{q}\right)^{t} \\
& +\left(u^{1}-u^{0}\right) q(1-q)(\ln \gamma) \sum_{t=1}^{\infty}\left(\delta \gamma^{q}\right)^{t}
\end{aligned}
$$

Letting $a=q$, and re-expressing the sums as starting at $t=0$, (A28) can be written as,

$$
\begin{aligned}
W \approx & \sum_{t=0}^{\infty}\left(\delta \gamma^{q}\right)^{t}\left(q u^{1}+(1-q) u^{0}\right) \\
& +(1 / 2)\left(q u^{1}+(1-q) u^{0}\right) q(1-q)(\ln \gamma)^{2} \sum_{t=0}^{\infty} t\left(\delta \gamma^{q}\right)^{t} \\
& +\left(u^{1}-u^{0}\right) q(1-q)(\ln \gamma)\left(\delta \gamma^{q}\right) \sum_{t=0}^{\infty}\left(\delta \gamma^{q}\right)^{t}
\end{aligned}
$$

Using the reduced forms of the infinite sums, the expression for social welfare simplifies to the expression given in the lemma. 


\section{CESifo Working Paper Series}

(for full list see www.cesifo.de)

1261 Joop Hartog, Hans van Ophem, and Simona Maria Bajdechi, How Risky is Investment in Human Capital?, August 2004

1262 Thomas Eichner and Rüdiger Pethig, Efficient Nonanthropocentric Nature Protection, August 2004

1263 David-Jan Jansen and Jakob de Haan, Look Who's Talking: ECB Communication during the First Years of EMU, August 2004

1264 David F. Bradford, The X Tax in the World Economy, August 2004

1265 Hans-Werner Sinn, Migration, Social Standards and Replacement Incomes. How to Protect Low-income Workers in the Industrialized Countries against the Forces of Globalization and Market Integration, August 2004

1266 Wolfgang Leininger, Fending off one Means Fending off all: Evolutionary Stability in Submodular Games, August 2004

1267 Antoine Bommier and Bertrand Villeneuve, Risk Aversion and the Value of Risk to Life, September 2004

1268 Harrie A. A. Verbon and Lex Meijdam, Too Many Migrants, Too Few Services: A Model of Decision-making on Immigration and Integration with Cultural Distance, September 2004

1269 Thomas Eichner and Rüdiger Pethig, Economic Land Use, Ecosystem Services and Microfounded Species Dynamics, September 2004

1270 Federico Revelli, Performance Rating and Yardstick Competition in Social Service Provision, September 2004

1271 Gerhard O. Orosel and Klaus G. Zauner, Vertical Product Differentiation When Quality is Unobservable to Buyers, September 2004

1272 Christoph Böhringer, Stefan Boeters, and Michael Feil, Taxation and Unemployment: An Applied General Equilibrium Approach, September 2004

1273 Assaf Razin and Efraim Sadka, Welfare Migration: Is the Net Fiscal Burden a Good Measure of its Economics Impact on the Welfare of the Native-Born Population?, September 2004

1274 Tomer Blumkin and Volker Grossmann, Ideological Polarization, Sticky Information, and Policy Reforms, September 2004 
1275 Katherine Baicker and Nora Gordon, The Effect of Mandated State Education Spending on Total Local Resources, September 2004

1276 Gabriel J. Felbermayr and Wilhelm Kohler, Exploring the Intensive and Extensive Margins of World Trade, September 2004

1277 John Burbidge, Katherine Cuff and John Leach, Capital Tax Competition with Heterogeneous Firms and Agglomeration Effects, September 2004

1278 Joern-Steffen Pischke, Labor Market Institutions, Wages and Investment, September 2004

1279 Josef Falkinger and Volker Grossmann, Institutions and Development: The Interaction between Trade Regime and Political System, September 2004

1280 Paolo Surico, Inflation Targeting and Nonlinear Policy Rules: The Case of Asymmetric Preferences, September 2004

1281 Ayal Kimhi, Growth, Inequality and Labor Markets in LDCs: A Survey, September 2004

1282 Robert Dur and Amihai Glazer, Optimal Incentive Contracts for a Worker who Envies his Boss, September 2004

1283 Klaus Abberger, Nonparametric Regression and the Detection of Turning Points in the Ifo Business Climate, September 2004

1284 Werner Güth and Rupert Sausgruber, Tax Morale and Optimal Taxation, September 2004

1285 Luis H. R. Alvarez and Erkki Koskela, Does Risk Aversion Accelerate Optimal Forest Rotation under Uncertainty?, September 2004

1286 Giorgio Brunello and Maria De Paola, Market Failures and the Under-Provision of Training, September 2004

1287 Sanjeev Goyal, Marco van der Leij and José Luis Moraga-González, Economics: An Emerging Small World?, September 2004

1288 Sandro Maffei, Nikolai Raabe and Heinrich W. Ursprung, Political Repression and Child Labor: Theory and Empirical Evidence, September 2004

1289 Georg Götz and Klaus Gugler, Market Concentration and Product Variety under Spatial Competition: Evidence from Retail Gasoline, September 2004

1290 Jonathan Temple and Ludger Wößmann, Dualism and Cross-Country Growth Regressions, September 2004

1291 Ravi Kanbur, Jukka Pirttilä and Matti Tuomala, Non-Welfarist Optimal Taxation and Behavioral Public Economics, October 2004 
1292 Maarten C. W. Janssen, José Luis Moraga-González and Matthijs R. Wildenbeest, Consumer Search and Oligopolistic Pricing: An Empirical Investigation, October 2004

1293 Kira Börner and Christa Hainz, The Political Economy of Corruption and the Role of Financial Institutions, October 2004

1294 Christoph A. Schaltegger and Lars P. Feld, Do Large Cabinets Favor Large Governments? Evidence from Swiss Sub-Federal Jurisdictions, October 2004

1295 Marc-Andreas Mündler, The Existence of Informationally Efficient Markets When Individuals Are Rational, October 2004

1296 Hendrik Jürges, Wolfram F. Richter and Kerstin Schneider, Teacher Quality and Incentives: Theoretical and Empirical Effects of Standards on Teacher Quality, October 2004

1297 David S. Evans and Michael Salinger, An Empirical Analysis of Bundling and Tying: Over-the-Counter Pain Relief and Cold Medicines, October 2004

1298 Gershon Ben-Shakhar, Gary Bornstein, Astrid Hopfensitz and Frans van Winden, Reciprocity and Emotions: Arousal, Self-Reports, and Expectations, October 2004

1299 B. Zorina Khan and Kenneth L. Sokoloff, Institutions and Technological Innovation During Early Economic Growth: Evidence from the Great Inventors of the United States, 1790 - 1930, October 2004

1300 Piero Gottardi and Roberto Serrano, Market Power and Information Revelation in Dynamic Trading, October 2004

1301 Alan V. Deardorff, Who Makes the Rules of Globalization?, October 2004

1302 Sheilagh Ogilvie, The Use and Abuse of Trust: Social Capital and its Deployment by Early Modern Guilds, October 2004

1303 Mario Jametti and Thomas von Ungern-Sternberg, Disaster Insurance or a Disastrous Insurance - Natural Disaster Insurance in France, October 2004

1304 Pieter A. Gautier and José Luis Moraga-González, Strategic Wage Setting and Coordination Frictions with Multiple Applications, October 2004

1305 Julia Darby, Anton Muscatelli and Graeme Roy, Fiscal Federalism, Fiscal Consolidations and Cuts in Central Government Grants: Evidence from an Event Study, October 2004

1306 Michael Waldman, Antitrust Perspectives for Durable-Goods Markets, October 2004

1307 Josef Honerkamp, Stefan Moog and Bernd Raffelhüschen, Earlier or Later: A General Equilibrium Analysis of Bringing Forward an Already Announced Tax Reform, October 2004 
1308 M. Hashem Pesaran, A Pair-Wise Approach to Testing for Output and Growth Convergence, October 2004

1309 John Bishop and Ferran Mane, Educational Reform and Disadvantaged Students: Are They Better Off or Worse Off?, October 2004

1310 Alfredo Schclarek, Consumption and Keynesian Fiscal Policy, October 2004

1311 Wolfram F. Richter, Efficiency Effects of Tax Deductions for Work-Related Expenses, October 2004

1312 Franco Mariuzzo, Patrick Paul Walsh and Ciara Whelan, EU Merger Control in Differentiated Product Industries, October 2004

1313 Kurt Schmidheiny, Income Segregation and Local Progressive Taxation: Empirical Evidence from Switzerland, October 2004

1314 David S. Evans, Andrei Hagiu and Richard Schmalensee, A Survey of the Economic Role of Software Platforms in Computer-Based Industries, October 2004

1315 Frank Riedel and Elmar Wolfstetter, Immediate Demand Reduction in Simultaneous Ascending Bid Auctions, October 2004

1316 Patricia Crifo and Jean-Louis Rullière, Incentives and Anonymity Principle: Crowding Out Toward Users, October 2004

1317 Attila Ambrus and Rossella Argenziano, Network Markets and Consumers Coordination, October 2004

1318 Margarita Katsimi and Thomas Moutos, Monopoly, Inequality and Redistribution Via the Public Provision of Private Goods, October 2004

1319 Jens Josephson and Karl Wärneryd, Long-Run Selection and the Work Ethic, October 2004

1320 Jan K. Brueckner and Oleg Smirnov, Workings of the Melting Pot: Social Networks and the Evolution of Population Attributes, October 2004

1321 Thomas Fuchs and Ludger Wößmann, Computers and Student Learning: Bivariate and Multivariate Evidence on the Availability and Use of Computers at Home and at School, November 2004

1322 Alberto Bisin, Piero Gottardi and Adriano A. Rampini, Managerial Hedging and Portfolio Monitoring, November 2004

1323 Cecilia García-Peñalosa and Jean-François Wen, Redistribution and Occupational Choice in a Schumpeterian Growth Model, November 2004 